\title{
Article \\ Validation of Eye Temperature Assessed Using Infrared Thermography as an Indicator of Welfare in Horses
}

\author{
Su-Min Kim ${ }^{1}{ }^{1}$ and Gil-Jae Cho ${ }^{1,2, *(\mathbb{D})}$ \\ 1 College of Veterinary Medicine, Kyungpook National University, Daegu 41566, Korea; liebe_sm@naver.com \\ 2 Institute of Equine Medicine, Kyungpook National University, Daegu 41566, Korea \\ * Correspondence: chogj@knu.ac.kr; Tel.: +82-053-950-5978
}

Citation: Kim, S.-M.; Cho, G.-J. Validation of Eye Temperature Assessed Using Infrared Thermography as an Indicator of Welfare in Horses. Appl. Sci. 2021, 11, 7186. https://doi.org/10.3390/ app11167186

Academic Editor: Carosena Meola

Received: 22 June 2021

Accepted: 2 August 2021

Published: 4 August 2021

Publisher's Note: MDPI stays neutral with regard to jurisdictional claims in published maps and institutional affiliations.

Copyright: (c) 2021 by the authors. Licensee MDPI, Basel, Switzerland. This article is an open access article distributed under the terms and conditions of the Creative Commons Attribution (CC BY) license (https:// creativecommons.org/licenses/by/ $4.0 /)$.

\begin{abstract}
This study aimed to validate eye temperature (ET) assessed using infrared thermography (IRT) as an indicator of welfare in horses. Moreover, this study aimed to determine the most accurate position for ET measured using IRT and to validate this approach as a gold-standard measurement method. As the quantitative data obtained by IRT have strongly influenced the ET results depending on the specific location of the measurement area, an accurate definition of the regions of interest (ROI) was established. A total of 176 horses (Thoroughbred, Warmblood, and Halla horses) were used at the racing course of the Korea Racing Authority and public horse-riding clubs in South Korea. The present study also compared temperatures among three ROIs of the eye-lacrimal sac, medial canthus, and lateral canthus-at rest. Correlations between ET, rectal temperature (RT), heart rate (HR), and respiratory rate (RR) were assessed. There were no significant correlations between HR, RR or RT; however, among the three ROIs, the temperature of the medial canthus was positively correlated with RT $(p<0.05)$. Furthermore, the size of ROI was negatively correlated with accuracy of temperature measurement. These results indicate that the most suitable area for ET measurement using IRT in horses is the medial canthus, and it is recommended to use the average temperature of the smallest ROIs ( $2 \times 2$ pixels) for temperature analysis. Therefore, this study offers a validated protocol in which ET measured using IRT in the horses is useful as an indicator of welfare.
\end{abstract}

Keywords: eye temperature; horse; infrared thermography; medial canthus; rectal temperature

\section{Introduction}

Horses (Equus caballus) are considered highly valuable in various industries and feature in many areas of society, including horseback riding, tourism, and horse-human companionship. In addition, the horseracing industry comprises a major proportion of horse owners [1]. In Korea, there are approximately 27,000 domesticated horses including 12,000 light horse breeds. Among these are Thoroughbreds and two pony branches, including the Jeju horse and the Halla horse, a cross between the Jeju and Thoroughbred horse [2]. There are three racetracks (Seoul, Busan, and Jeju) and approximately 500 riding course clubs, which include those in the public sector [1]. In relation to minimizing stressors, there has been an increase in public concern regarding the welfare of racing horses in South Korea; however, it is still in its infancy.

Farm animals become stressed when they are exposed to adverse environmental conditions, causing a range of unfavorable consequences, from discomfort to death [3]. Different methodologies for stress assessment among animals have been developed. Until recently, the main measurement of stress in animals has been the concentrations of cortisol in their blood, feces, and saliva [4,5]. Additional parameters for stress determination (employed in various equestrian competitions) are heart rate (HR), respiratory rate (RR), and rectal temperature (RT) [6-8]. However, the techniques used to obtain these measurements (blood sample collection, animal handling, etc.) can create additional stress, hence biasing the stress measures obtained [9] particularly in animals that are familiar with human 
management. Hence, the use of minimally invasive methodologies for stress assessment is advisable to assess animal welfare in this species. One of the ways to minimize stress in horses is IRT imaging.

Infrared thermography (IRT) can detect infrared radiation emitted from an object, which is a measure of its surface temperature (ST), and can present it as a heat map [10]. IRT has been widely used as an auxiliary diagnostic tool for diagnosing musculoskeletal disorders in horses [11-13]. Moreover, IRT has emerged as a noninvasive and reliable method for assessing physiological stress in working [14,15], companion [10,16], and production animals $[17,18]$. However, the quantitative data obtained from infrared thermography (IRT) show that even the slightest incorrect use can lead to substantial inaccuracies in the measurement of body temperature [19]. Piccinini et al. [19] demonstrated that working distance, body-device angle, and light conditions can strongly impact temperature measurements, which could invalidate the screening results. In addition, Ring et al. [20] reported that the collection of normal reference images is required, but it depends on the improvement of the reliability and cross calibration of camera systems. It is difficult to obtain reliable measurement values, especially in horse breeding environments, but studies that attempt quantitative measurements are increasing [21-24]. Therefore, this study aimed to determine the most accurate position for eye temperature (ET) measured using IRT and to validate this approach as a gold-standard measurement method.

Recent studies have used IRT to measure eye temperature (ET), which may reflect changes in body temperature in response to events and stimuli $[10,14,25,26]$. Several IRT studies have shown that ET is significantly correlated with core body temperature compared with the ST of other anatomical regions $[10,14,25,26]$. This association is attributed to the proximity of the orbit to the brain, as well as the rich blood supply it receives [27,28]. A decrease and increase in ET may reflect a stress response dominated by the sympathetic nervous system [29] and the parasympathetic nervous system, respectively [30,31]. An increase in ET may reflect general stress in a race meet, caused by transportation, race anticipation, and the race itself.

ET assessed using IRT has recently been considered as an appropriate tool for stress and health assessment in other animals [27]. However, there are no studies on standardized protocols for temperature analysis methods. This study aimed to validate whether the assessment of ET by IRT, a noninvasive tool, correlates with RT among horses. This study also investigated whether the measurement of temperature in specific areas, such the lacrimal sac, medial canthus, and lateral canthus of the eye, using IRT, can efficiently reflect RT. In addition, the thermal image analysis method was used to accurately assess values according to the pixel size of the regions of interest (ROIs).

\section{Materials and Methods}

\subsection{Ethical Statement}

The protocol and conduct of this study were approved by the Kyungpook National University of Animal Ethics Committee, Republic of Korea (KNU2019-0091).

\subsection{Animals}

In total, 176 horses (72 mares and 104 geldings, aged $2-18,8.93 \pm 4.58$ (mean $\pm \mathrm{SD}$ ) years), were enrolled in this study; these included Thoroughbred, Warmblood, and Halla breeds (a hybridization between Thoroughbred and Jeju horses in South Korea) raised in the racing courses of the Korea Racing Authority and public horse-riding clubs during winter. After ethical approval, the owners of all horses agreed to sample collection. The horses rested in their individual stables for $24 \mathrm{~h}$, except when exercising or horse riding. Each horse was placed in the stock and the ET, RT, HR, and RR were assessed at rest.

\subsection{Infrared Thermography}

IRT was performed to obtain 352 images, which were collected from 176 horses. Efforts were made to minimize the impact of external environmental conditions on the 
measured values where possible. To minimize the impact of the external environmental conditions, IRT images were collected in enclosed spaces, free from wind and sunlight exposure. Although the horses were familiar with human interactions, they were curious about the camera but did not resist. As dust and foreign substances on the horse's facial area could affect the temperature measurement, it was removed with a face brush $15 \mathrm{~min}$ before filming.

The IRT image was taken by the same researcher using an infrared radiation camera (T420, FLIR Systems Inc., Wilsonville, OR, USA) while the animal rested on the stall box. Thermal imaging cameras require a calibration procedure. The radiation rate of this thermal camera was $0.98(\varepsilon)$ (the emissivity for mammalian skin), and calibration uncertainty on absolute temperature was $0.9^{\circ} \mathrm{C}$ (the confidence level was approximately $95 \%)$. The ambient temperature and relative humidity were recorded using a digital thermohygrometer (HT-7, Hubdic, Korea) (Table 1), and these recorded values were inputted into the thermal camera while shooting, to obtain the corrected result.

Table 1. Ambient temperature $\left({ }^{\circ} \mathrm{C}\right)$ and humidity $(\%)$ conditions according to season during infrared thermography (IRT).

\begin{tabular}{cccccc}
\hline $\begin{array}{c}\text { Environmental } \\
\text { Factors }\end{array}$ & Month & Minimum & Maximum & Mean & $\begin{array}{c}\text { Standard } \\
\text { Deviation }\end{array}$ \\
\hline & February & 7.2 & 11.8 & 9.03 & 1.72 \\
Ambient & November & 13.8 & 20.4 & 17.53 & 2.76 \\
temperature $\left({ }^{\circ} \mathrm{C}\right)$ & December & 6.6 & 14.1 & 11.5 & 2.6 \\
& January & 10.7 & 12.9 & 11.8 & 1.1 \\
\hline & February & 55.8 & 62.9 & 58.08 & 2.9 \\
Relative & November & 45.9 & 76.8 & 58.03 & 13.46 \\
humidity $(\%)$ & December & 45.9 & 74.3 & 56.56 & 9.54 \\
& January & 51.1 & 55 & 53.05 & 1.95 \\
\hline
\end{tabular}

For quantitative IRT evaluation, the eye regions (left and right) were calibrated with a camera angle of approximately $90^{\circ}$ from the sagittal plane of the horses [21] and a distance of approximately $30-50 \mathrm{~cm}$ from the horses. Two images were obtained from each horse per image session and took approximately $30 \mathrm{~s}$ to shoot.

\section{4. $R T, H R$, and $R R$}

After the first thermographic examination, RT was taken with an electronic veterinary rectal thermometer (CE0123, Mebby Flexo, Italy), emitting an acoustic signal when the attained temperature remained stable for $>15 \mathrm{~s}$.

An electronic stethoscope (E3200, 3M Littmann, St. Paul, MN, USA) was used to automatically record HR for $15 \mathrm{~s}$ behind the left elbow of the horse.

$\mathrm{RR}$ was assessed by counting the respiratory movements of the flank or nostril for $15 \mathrm{~s}$ and then multiplying by four (movements/min).

Care was taken to minimize stress during the sampling. Throughout the study, the animals were handled by the same person, and sampled by the same operators.

\subsection{Data Analysis}

IRT images were analyzed using a specialized software (FLIR Tools Professional, Teledyne FLIR Systems Inc., OR, USA). The measurement was performed on the skin areas around the eyes, lacrimal sac, medial canthus (especially lacrimal caruncle), and lateral canthus (Figure 1). 


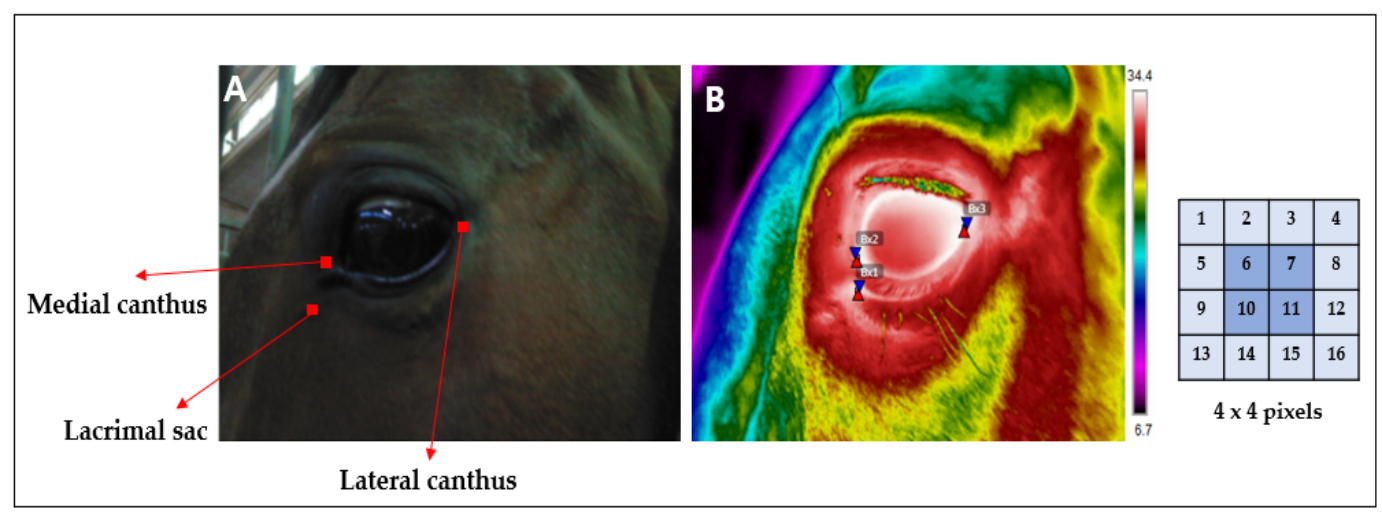

Figure 1. Three regions of interest (ROIs) of the eye for temperature measurement in horses. The size of each ROI was $4 \times 4$ pixels, in which the max and mean temperature are measured, and $2 \times 2$ pixels mean the center of the $4 \times 4$ pixels. (A): Image of a horse's left eye; (B): Image of a horse's left eye by IRT; Bx 1: Lacrimal sac; Bx 2: Medial canthus; Bx 3: Lateral canthus.

Since the limited size of the ROIs can strongly influence the temperature result depending on the measurement location, it was defined as follows:

(1) Find the three points representing the maximum temperature in the three areas (lacrimal sac, medial canthus, and lateral canthus).

(2) One $4 \times 4$ pixel area including the maximum temperature is defined as one ROI, and three ROIs are measured per image.

(3) $2 \times 2$ pixels indicates the center area of $4 \times 4$ pixels.

Those ROIs were chosen to minimize unnecessary information and to display the temperature more accurately when reading the average pixels compared to the value of a single pixel.

\subsection{Statistical Analysis}

Numerical and categorical characteristics are expressed as mean \pm standard deviation.

The statistical bias correction method was used to correct the changes depending on the environment and to increase consistency with RT. The method used here is Quantile Matching [32].

To quantitatively assess the performance of ET, the present study calculated the root mean square error (RMSE) and quantile root mean square error (QRMSE) [33]. The RMSE and QRMSE were defined as follows:

$$
\begin{array}{r}
R M S E=\sqrt{\sum \frac{\left(y_{\text {pred }}-y_{\text {true }}\right)^{2}}{n}} \\
\text { QRMSE }=\sqrt{\sum \frac{\left(\operatorname{Rank}_{\left(y_{\text {pred }}\right)}-\operatorname{Rank}_{\left(y_{\text {true }}\right)}\right)^{2}}{n}}
\end{array}
$$

where $y_{\text {pred }}$ and $y_{\text {true }}$ denote the mean of the $4 \times 4$ pixels, $2 \times 2$ pixels, and RT in each horse, respectively. Rank () denotes the quantile-quantile of data. In addition, data distribution could denote differences in ET measurements according to region using a histogram, which was designed to compare the quantitative superiority of several thermography results. Moreover, a correlation analysis between ET in the three ROIs and RT was performed.

All statistical measurements were performed using Python version 3.7, Sklearn package 0.23.2 (Python Software Foundation, Wilmington, DE, USA), and Statistical Package for the Social Sciences software (version 25, IBM SPSS Statistics, Chicago, IL, USA). $p$ value $<0.05$ was considered statistically significant. 


\section{Results}

\subsection{Correlation between $E T, R T, H R$, and $R R$}

The normal ET, RT, HR, and RR of horses are shown in Table 2. The average temperatures of the lacrimal sac, medical canthus, and lateral canthus among healthy horses were $34.86^{\circ} \mathrm{C}, 35.33{ }^{\circ} \mathrm{C}$, and $34.15^{\circ} \mathrm{C}$, respectively. In addition, the average RT was $37.70{ }^{\circ} \mathrm{C}$, and the HR and RR were 37 beats/min and $23.67 \mathrm{cycle} / \mathrm{min}$, respectively. There was a low significant correlation between $\mathrm{HR}$ and RR as well as RT.

Table 2. Correlation between eye temperature (ET, ${ }^{\circ} \mathrm{C}$ : left and right) and heart rate (HR, beat $\left./ \mathrm{min}\right)$, and respiratory rate $(\mathrm{RR}$, cycles $/ \mathrm{min})$ for each instance of rectal temperature $\left(\mathrm{RT},{ }^{\circ} \mathrm{C}\right)$ recorded in 176 horses.

\begin{tabular}{cccccccc}
\hline \multirow{2}{*}{$\boldsymbol{n} \boldsymbol{n}=\mathbf{1 7 6})$} & \multicolumn{3}{c}{ ET } & RT & HR & RR \\
\cline { 2 - 4 } & LS & MC & LC & & & \\
\hline Mean & 34.86 & 35.33 & 34.15 & 37.7 & 37 & 23.67 \\
SD & 1.01 & 1.01 & 1.02 & & 0.29 & 11.33 & 5.75 \\
Min & 29.7 & 32.5 & 29.0 & 37 & 21 & 12 \\
Max & 37.1 & 38.2 & 36.7 & 38.2 & 60 & 36 \\
CV (\%) & 2.18 & 2.14 & 2.25 & & 1.01 & 31.25 & 36.98 \\
CC & 0.3048 & 0.3392 & 0.2073 & 1.00 & 0.088 & 0.032 \\
\hline
\end{tabular}

LC, lacrimal sac; MC, medial canthus; LC, lateral canthus; SD, standard deviation; CV (\%), coefficient variation CC, correlation coefficients.

The average temperature of the medial canthus was closest to the RT, and the coefficient of variation was the lowest among the three areas of the eyes as well as RR and HR. In addition, the correlation analysis showed that while the temperature of the medial canthus was low as a reliable value, it was most related to the RT.

\subsection{Efficacy of IRT in Assessing the Temperature of the Horse's Eyes}

The temperatures of the three ROIs are shown in Table 3. The medial canthus had the highest temperature in the three areas of both eyes. In addition, in the medial canthus region, the temperature of the center area $(2 \times 2$ pixels) in the $4 \times 4$ pixels was higher (by approximately $0.16^{\circ} \mathrm{C}-0.20^{\circ} \mathrm{C}$ ) than that of the $4 \times 4$ pixels.

Table 3. Maximum, mean temperature, root mean square error (RMSE), and quantile RMSE (QRMSE) of the three ROIs in the horse's eyes for each rectal temperature $\left(\mathrm{RT},{ }^{\circ} \mathrm{C}\right)$.

\begin{tabular}{|c|c|c|c|c|c|c|c|c|c|c|}
\hline \multirow{2}{*}{\multicolumn{2}{|c|}{ Total $(n=176)$}} & \multicolumn{6}{|c|}{$4 \times 4$ Pixels } & \multicolumn{3}{|c|}{$2 \times 2$ Pixels } \\
\hline & & $\operatorname{Max}\left({ }^{\circ} \mathrm{C}\right)$ & RMSE & QRMSE & Mean $\left({ }^{\circ} \mathrm{C}\right)$ & RMSE & QRMSE & Mean $\left({ }^{\circ} \mathrm{C}\right)$ & RMSE & QRMSE \\
\hline \multirow{3}{*}{ Left } & LS & $35.10 \pm 1.02$ & 2.49 & 2.35 & $34.94 \pm 1.05$ & 2.65 & 2.52 & $35.05 \pm 1.05$ & 2.60 & 2.47 \\
\hline & $\mathrm{MC}$ & $35.72 \pm 0.97$ & 1.84 & 1.63 & $35.40 \pm 1.05$ & 2.14 & 1.96 & $35.56 \pm 1.03$ & 1.92 & 1.75 \\
\hline & LC & $34.42 \pm 0.96$ & 3.32 & 3.20 & $34.16 \pm 1.07$ & 3.53 & 3.42 & $34.28 \pm 1.04$ & 3.46 & 3.35 \\
\hline \multirow{3}{*}{ Right } & LS & $35.08 \pm 0.92$ & 2.56 & 2.50 & $34.90 \pm 0.99$ & 2.71 & 2.58 & $35.00 \pm 0.98$ & 2.67 & 2.54 \\
\hline & $\mathrm{MC}$ & $35.78 \pm 0.92$ & 1.70 & 1.62 & $35.43 \pm 1.01$ & 2.04 & 1.84 & $35.63 \pm 0.96$ & 1.89 & 1.69 \\
\hline & $\mathrm{LC}$ & $34.56 \pm 0.97$ & 3.27 & 3.23 & $34.36 \pm 1.01$ & 3.45 & 3.34 & $34.46 \pm 1.01$ & 3.41 & 3.30 \\
\hline
\end{tabular}

ROI, region of interest; LS, lacrimal sac; MC, medial canthus; LS, lateral canthus.

Table 3 shows that the RMSE and QRMSE $(p<0.0001)$ of the three ROIs in the horse's eyes for each instance of RT had values closer to 0 , indicating better results. The RMSE and QRMSE before correction had a value of 1.6 or more (Table 3). As shown in Table 4, after correction, they were less than 0.4 to 1.1, respectively. Therefore, the RMSE and QRMSE in $2 \times 2$ pixels displayed the best results in the medial canthus after statistical bias correction. 
Table 4. Maximum, mean temperature, root mean square error (RMSE), and quantile RMSE (QRMSE) results of three ROIs in the horse's eyes for each rectal temperature $\left(\mathrm{RT},{ }^{\circ} \mathrm{C}\right)$ after statistical bias correction.

\begin{tabular}{ccccccccccc}
\hline \multirow{2}{*}{ Total $(\boldsymbol{n}=\mathbf{1 7 6})$} & \multicolumn{9}{c}{$\mathbf{4} \times \mathbf{4}$ Pixels } & \multicolumn{3}{c}{$\mathbf{2} \times \mathbf{2}$ Pixels } \\
\cline { 3 - 11 } & & $\mathbf{M a x}\left({ }^{\circ} \mathbf{C}\right)$ & RMSE & QRMSE & Mean $\left({ }^{\circ} \mathbf{C}\right)$ & RMSE & QRMSE & Mean $\left({ }^{\circ} \mathbf{C}\right)$ & RMSE & QRMSE \\
\hline \multirow{3}{*}{ Left } & LS & $35.77 \pm 0.85$ & 0.9781 & 0.5379 & $35.59 \pm 0.85$ & 0.9809 & 0.5417 & $35.66 \pm 0.83$ & 0.9522 & 0.5165 \\
& MC & $35.77 \pm 0.83$ & 0.9646 & 0.4948 & $35.59 \pm 0.87$ & 1.0061 & 0.5398 & $35.66 \pm 0.77$ & 0.8939 & 0.4584 \\
& LC & $35.77 \pm 0.86$ & 1.0198 & 0.5369 & $35.59 \pm 0.86$ & 1.0103 & 0.5370 & $35.66 \pm 0.85$ & 0.9881 & 0.5292 \\
\hline \multirow{3}{*}{ Right } & LS & $35.80 \pm 0.84$ & 0.9664 & 0.5116 & $35.62 \pm 0.82$ & 0.9543 & 0.5062 & $35.68 \pm 0.82$ & 0.9574 & 0.5086 \\
& MC & $35.80 \pm 0.82$ & 0.9151 & 0.5033 & $35.62 \pm 0.81$ & 0.9823 & 0.4902 & $35.68 \pm 0.79$ & 0.8664 & 0.4815 \\
& LC & $35.80 \pm 0.93$ & 1.0412 & 0.6014 & $35.62 \pm 0.89$ & 1.0134 & 0.5717 & $35.68 \pm 0.92$ & 1.0398 & 0.5985 \\
\hline
\end{tabular}

ROI, region of interest; LS, lacrimal sac; MC, medial canthus; LS, lateral canthus.

\section{Discussion}

Compared with conventional imaging techniques, IRT is advantageous as it can facilitate a quicker and more accurate diagnosis of physiological changes in ROIs [34]. Moreover, it is a noncontact, noninvasive diagnostic technique, which can measure physiological function by recording the exothermal status of the infrared rays emitted [35-37]. The skin temperature depends on the underlying tissue metabolism and local blood circulation. Therefore, the changes in physiological activity result in abnormal thermal patterns. Alterations in cutaneous blood flow and sweat patterns occur in the case of overload and inflammation [38]. Researchers suggest that ET obtained using IRT can be used to assess fever or stress in horses $[15,27,39]$. A higher ET may be correlated with ocular vasodilation, causing greater heat dissipation (identified using IRT), specifically in the lacrimal caruncle, which contains capillaries controlled by the sympathetic nerves $[15,27,39]$.

Although several studies have also shown that the medial canthus, particularly the lacrimal caruncle, is an optimal location for measuring ET, there are no standards for measurement and analysis methods [21-24]. Jansson et al. [22] obtained 791 images in 32 horses and measured the maximal ET in the medial posterior palpebral border of the lower eyelid and the lacrimal caruncle in the circular area with a diameter of $1 \mathrm{~cm}$. In addition, Trindade et al. [23] evaluated the maximum and mean eye ST at the commissure region of the lacrimal caruncle in the circular area with a 22-pixels radius in 12 horses.

However, recent efforts have attempted to designate a reference point or standardization method. Ijichi et al. [21] determined whether the position of the IRT camera had an impact on recorded temperature and which camera position was optimal for indicating stress in 14 horses. This suggests that a $90^{\circ}$ angle in relation to the sagittal plane in a mammal with anterolateral eyes is the optimal position for taking ET measurements using IRT. Further, Kim et al. [33] studied the correlation between tympanic and facial temperatures in 508 humans. The results showed that the tympanic membrane temperature and medial canthus were the most similar. Moreover, a model was developed to predict tympanic temperature through statistical bias correction. These studies which attempted to define that standardization were incorporated into this study, resulting in higher accuracy and detail compared with previous studies that measured horse ET.

In this study, the measurement area was localized to minimize unnecessary information, and the correlation between RT and ET measured at three areas in 172 horses (352 images) was quantitatively analyzed. The quantitative data obtained from IRT strongly influenced the ET result depending on the specific location of the measurement area; therefore, in this study, the $4 \times 4$ pixel area, including the maximum temperature, was defined as the ROI. The maximum temperature was more correlated with RT compared with the average temperature of $4 \times 4$ or $2 \times 2$ pixels. However, the maximum temperature is a single pixel value and has a high efficacy in indicating the maximum or minimum value with a defective pixel. Therefore, this study suggests that the approach is only valid when the camera is properly calibrated and there is no image non-uniformity to prevent a single pixel value from not significantly affecting the outcome. 
For animals, maintaining the homeostasis of body temperature can be important because it is an indicator of health. The most suitable for ET measurement is medial canthus, and use of the average temperature of the smallest ROIs $(2 \times 2$ pixels $)$ is recommended for temperature analysis. Moreover, it is suggested that the measurement distance is maintained at $30-50 \mathrm{~cm}$ and $90^{\circ}$ to the sagittal plane. This study offers a validated protocol for using IRT to measure stress and welfare. Regarding animal welfare, it is observed that it is sufficient to use ET to verify whether ET can be used as an indicator of health. Further studies are warranted to evaluate the utility of the measured ET in assessing stress levels and pain states in horses.

\section{Conclusions}

This study was conducted to validate ET assessed using IRT as an indicator of welfare in horses. Moreover, this study offers a validated protocol in which ET measured using IRT in the horses is useful as an indicator of welfare. The most suitable region for ET measurement is the medial canthus, and it is recommended to use the average temperature of the smallest ROIs ( $2 \times 2$ pixels) for temperature analysis. Further studies are warranted to evaluate the utility of the measured ET for assessing stress levels and pain states in horses.

Author Contributions: Conceptualization, S.-M.K. and G.-J.C.; Methodology, S.-M.K.; software, S.-M.K.; validation, S.-M.K. and G.-J.C.; formal analysis, S.-M.K. and G.-J.C.; investigation, S.-M.K.; resources, S.-M.K. and G.-J.C.; data curation, S.-M.K.; writing-original draft preparation, S.-M.K.; writing-review and editing, S.-M.K. and G.-J.C.; visualization, S.-M.K. and G.-J.C.; supervision, G.-J.C.; project administration, G.-J.C.; funding acquisition, G.-J.C. All authors have read and agreed to the published version of the manuscript.

Funding: This research was supported by the National Research Foundation of Korea Funded by the Ministry of Education, Science and Technology (NRF-2020R1I1A3067905).

Institutional Review Board Statement: Not applicable.

Informed Consent Statement: Not applicable.

Conflicts of Interest: The authors declare no conflict of interest.

\section{References}

1. Shin, S.K.; Kim, S.M.; Lioyd, S.; Cho, G.J. Prevalence of hoof disorders in horses in South Korea. Open Agr. J. 2020, 14, 25-29. [CrossRef]

2. Seo, M.G.; Yun, S.H.; Choi, S.K. Seroprevalence of equine piroplasms in the Republic of Korea. Vet. Parasitol. 2011, 179, 224-226. [CrossRef] [PubMed]

3. Etim, N.N.; Williams, M.E.; Evans, E.I.; Offiong, E.E.A. Physiological and behavioral responses of farm animals to stress: Implication to animal productivity. Am. J. Adv. Agric. Res. 2013, 1, 153-161.

4. van der Kolk, J.H.; Nachreiner, R.F.; Schott, H.C.; Refsal, K.R.; Zanella, A.J. Salivary and plasma concentration of cortisol in normal horses and horses with Cushing's disease. Equine Vet. J. 2001, 33, 211-213. [CrossRef]

5. Peeters, M.; Sulon, J.; Beckers, J.F.; Ledoux, D.; Vandeheede, M. Comparison between blood serum and salivary cortisol concentrations in horses using an adrenocorticotropic hormone challenge. Equine Vet. J. 2011, 43, 487-493. [CrossRef]

6. Peeters, M.; Sulon, J.; Serteyn, D.; Vandeheede, M. Assessment of stress level in horses during competition using salivary cortisol: Preliminary studies. J. Vet. Behav. Clin. Appl. Res. 2010, 5, 216. [CrossRef]

7. Schmidt, A.; Möstl, E.; Wehnert, C.; Aurich, J.; Müller, J.; Aurich, C. Cortisol release and heart rate variability in horses during road transport. Horm. Behav. 2010, 57, 209-215. [CrossRef] [PubMed]

8. Kay, R.; Hall, C.A. The use of a mirror reduces isolation stress in horses being transported by trailer. Appl. Anim. Behav. Sci. 2009, 116, 237-243. [CrossRef]

9. Stewart, M.; Webster, J.R.; Schaefer, A.L.; Cook, N.J.; Scott, S.L. Infra-red thermography as a non-invasive tool to study animal welfare. Anim. Welf. 2005, 14, 319-325.

10. Travain, T.; Colombo, E.S.; Heinzl, E.; Bellucci, D.; Prato Previde, E.; Valsecchi, P. Hot dogs: Thermography in the assessment of stress in dog (Canis familiaris)-A pilot study. J. Vet. Behav. 2015, 10, 17-23. [CrossRef]

11. Eddy, A.L.; Van Hoogmoed, L.M.; Snyder, J.R. The role of thermography in the management of equine lameness. Vet. J. 2001, 162, 172-181. [CrossRef]

12. Smith, W.M. Applications of the thermography in veterinary medicine. Ann. N. Y. Acad. Sci. 1964, 121, 248-254. [CrossRef] 
13. Turner, T.A. Thermography as an aid to the clinical lameness evaluation. Vet. Clin. N. Am. Equine Pract. 1991, 7, 311-338. [CrossRef]

14. Bartolomé, E.; Sánchez, M.J.; Molina, A.; Schaefer, A.L.; Cervantes, I.; Valera, M. Using eye temperature and heart rate for stress assessment in young horses competing in jumping competitions and its possible influence on sport performance. Animal 2013, 7 , 2044-2053. [CrossRef]

15. Dai, F.; Cogi, N.H.; Heinzl, E.U.L.; Dalla Costa, E.; Canali, E.; Minero, M. Validation of a fear test in sport horses using infrared thermography. J. Vet. Behav. 2015, 10, 128-136. [CrossRef]

16. Riemer, S.; Assis, L.; Pike, T.W.; Mills, D.S. Dynamic changes in ear temperature in relation to separation distress in dogs. Physiol. Behav. 2016, 167, 86-91. [CrossRef]

17. Edgar, J.L.; Nicol, C.J.; Pugh, C.A.; Paul, E.S. Surface temperature changes in response to handling in domestic chickens. Physiol. Behav. 2013, 119, 195-200. [CrossRef] [PubMed]

18. McManus, C.; Tanure, C.B.; Peripolli, V.; Seixas, L.; Fischer, V.; Gabbi, A.M.; Menegassi, S.R.O.; Stumpf, M.T.; Kolling, G.J.; Dias, E.; et al. Infrared thermography in animal production: An overview. Comput. Electron. Agric. 2016, 123, 10-16. [CrossRef]

19. Piccinini, F.; Martinelli, G.; Carbonaro, A. Reliability of body temperature measurements obtained with contactless infrared point thermometers commonly used during the COVID-19 pandemic. Sensors 2021, 21, 3794. [CrossRef] [PubMed]

20. Ring, E.F.J.; Ammer, K.; Wiecek, B.; Plassmann, P.; Jones, C.D.; Jung, A.; Murawski, P. Quality assurance for thermal imaging systems in medicine. Thermol. Int. 2007, 17, 103-106.

21. Ijichi, C.; Evans, L.; Woods, H.; Yarnell, K. The right angle: Validating a standardised protocol for the use of infra-red thermography of eye temperature as a welfare indicator. Anim. Welf. 2020, 29, 123-131. [CrossRef]

22. Jansson, A.; Lindgren, G.; Velie, B.D.; Sole, M. An investigation into factors influencing basal eye temperature in the domestic horse (Equus caballus) when measured using infrared thermography in field conditions. Physiol. Behav. 2020, 228, 113-118. [CrossRef]

23. Trindade, P.H.; de Camargo Ferraz, G.; Pereira Lima, M.L.; Negrão, J.A.; Paranhos da Costa, M.J.R. Eye surface temperature as a potential indicator of physical fitness in ranch horses. J. Equine Vet. Sci. 2019, 75, 1-8. [CrossRef]

24. Fenner, K.; Yoon, S.; White, P.; Starling, M.; McGreevy, P. The effect of noseband tightening on horses' behavior, eye temperature, and cardiac responses. PLoS ONE 2016, 11, e0154179. [CrossRef]

25. Church, J.S.; Hegadoren, P.R.; Paetkau, M.J.; Miller, C.C.; Regev-Shoshani, G.; Schaefer, A.L.; Schwartzkopf-Genswein, K.S. Influence of environmental factors on infrared eye temperature measurements in cattle. Res. Vet. Sci. 2014, 96, 220-226. [CrossRef]

26. Herborn, K.A.; Graves, J.L.; Jerem, P.; Evans, N.P.; Nager, R.; McCafferty, D.J.; McKeegan, D.E.F. Skin temperature reveals the intensity of acute stress. Physiol. Behav. 2015, 152, 225-230. [CrossRef]

27. Stewart, M.; Webster, J.R.; Verkerk, G.A.; Schaefer, A.L.; Colyn, J.J.; Stafford, K.J. Non-invasive measurement of stress in dairy cows using infrared thermography. Physiol. Behav. 2007, 92, 520-525. [CrossRef] [PubMed]

28. Sutherland, M.A.; Worth, G.M.; Dowling, S.K.; Lowe, G.L.; Cave, V.M.; Stewart, M. Evaluation of infrared thermography as a non-invasive method of measuring the autonomic nervous response in sheep. PLoS ONE 2020, 2020 15, e0233558. [CrossRef]

29. Stewart, M.; Stafford, K.J.; Dowling, S.K.; Schaefer, A.L.; Webster, J.R. Eye temperature and heart rate variability of calves disbudded with or without local anaesthetic. Physiol. Behav. 2008, 93, 789-797. [CrossRef] [PubMed]

30. Cook, N.; Schaefer, A.; Warren, L.; Burwash, L.; Anderson, M.; Baron, V. Adrenocortical and metabolic responses to ACTH injection in horses: An assessment by salivary cortisol and infrared thermography of the eye. Can. J. Anim. Sci. 2001, 81, 621.

31. Valera, M.; Bartolomé, E.; Sánchez, M.J.; Molina, A.; Cook, N.; Schaefer, A. Changes in eye temperature and stress assessment in horses during show jumping competitions. J. Equine Vet. Sci. 2012, 32, 827-830. [CrossRef]

32. Bourlai, T.; Pryor, R.R.; Syyama, J.; Reis, S.E.; Hostler, D. Use of thermal imagery for estimation of core body temperature during precooling, exertion, and recovery in wildland firefighter protective clothing. Prehosp. Emerg. Care 2012, 16, 390-399. [CrossRef] [PubMed]

33. Kim, D.W.; Zhang, H.Y.; Yoo, J.H.; Park, Y.S.; Song, H.J.; Yang, K.H. The correlation between tympanic membrane temperature and specific region of face temperature. Quant. Infrared Thermogr. J. 2019, 16, 1-7. [CrossRef]

34. Otilia, C.; Tanase, A.; Miclaus, I. Digital infrared thermography in assessing soft tissues injuries on sport equines. Bull. USAMV-CN 2006, 63, 228-233. [CrossRef]

35. Clark, J.A.; Cena, K. The Potential of infrared thermography in veterinary diagnosis. Vet. Rec. 1977, 100, 402-404. [CrossRef]

36. Purohit, R.C.; McCoy, M.D.; Bergfeld, W.A. Thermographic diagnosis of Horner's syndrome in the horse. Am. J. Vet. Res. 1980, 41, 1180-1182. [PubMed]

37. Turner, T.A.; Purohit, R.C.; Fessler, J.F. Thermography: A review in equine medicine. Compend. Contin. Educ. Vet. 1986, 8, 855-862.

38. Masko, M.; Krajewska, A.; Zdrojkowski, L.; Domino, M.; Gajewski, Z. An application of temperature mapping of horse's back for leisure horse-rider-matching. Anim. Sci. J. 2019, 90, 1396-1406. [CrossRef] [PubMed]

39. Yarnell, K.; Hall, C.; Billett, E. An assessment of the aversive nature of an animal management procedure (clipping) using behavioral and physiological measures. Physiol. Behav. 2013, 118, 32-39. [CrossRef] [PubMed] 